\title{
BMJ Open Adjusted indices of multiple deprivation to enable comparisons within and between constituent countries of the UK including an illustration using mortality rates
}

\author{
Gary A Abel, ${ }^{1,2}$ Matthew E Barclay, ${ }^{2}$ Rupert A Payne ${ }^{2,3}$
}

To cite: Abel GA, Barclay ME, Payne RA. Adjusted indices of multiple deprivation to enable comparisons within and between constituent countries of the UK including an illustration using mortality rates. BMJ Open 2016;6: e012750. doi:10.1136/ bmjopen-2016-012750

- Prepublication history and additional material is available. To view please visit the journal (http://dx.doi.org/ 10.1136/bmjopen-2016012750).

Received 23 May 2016 Revised 23 August 2016 Accepted 12 October 2016

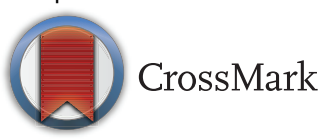

\footnotetext{
${ }^{1}$ University of Exeter Medical School, Exeter, UK

2Primary Care Unit, Cambridge Centre for Health Services Research, Institute of Public Health, Forvie Site, University of Cambridge School of Clinical Medicine, Cambridge, Cambridgeshire, UK

${ }^{3}$ Centre for Academic Primary Care, School of Social and Community Medicine, University of Bristol, Bristol, UK
}

Correspondence to Dr Gary A Abel; g.a.abel@exeter.ac.uk

\section{ABSTRACT}

Objectives: Social determinants can have a major impact on health and as a consequence substantial inequalities are seen between and within countries. The study of inequalities between countries relies on having accurate and consistent measures of deprivation across the country borders. However, in the UK most socioeconomic deprivation measures are not comparable between countries. We give a method of adjusting the Indices of Multiple Deprivation (IMD) for use across the UK, describe the deprivation of each UK country, and show the problems introduced by naïvely using country-specific deprivation measures in a UK-wide analysis of mortality rates.

Setting/participants: 42148 geographic areas covering the population of the UK.

Outcome measures: Adjusted IMD scores based on the income and employment domains of countryspecific IMD scores, adjusting for the contribution of other domains. The mortality rate among people aged under 75 years standardised to the UK age structure was compared between country-specific and UK-adjusted IMD quintiles.

Results: Of the constituent countries of the UK, Northern Ireland was the most deprived with $37 \%$ of the population living in areas in the most deprived fifth of the UK, followed by Wales with $22 \%$ of the population living in the most deprived fifth of the UK. England and Scotland had similar levels of deprivation. Deprivation-specific mortality rates were similar in England and Wales. Northern Ireland had lower mortality rates than England for each deprivation group, with similar differences for each group. Scotland had higher mortality rates than England for each deprivation group, with larger differences for more deprived groups.

Conclusions: Analyses of between-country and within-country inequalities by socioeconomic position should use consistent measures; failing to use consistent measures may give misleading results. The published adjusted IMD scores we describe allow consistent analysis across the UK.

\section{Strengths and limitations of this study}

- We employ a transparent methodology using open data to produce consistent UK-wide indices of deprivation for small-area statistical geographies.

- The analysis includes data from all small-area census geographies in the UK.

- The adjusted index is constructed using information from all domains of the original indices of multiple deprivation, rather than income and/or employment alone.

- The source data for different countries relate to different years, which may introduce error to UK-wide indices.

- No gold-standard measure of deprivation exists to confirm the accuracy of the results for small areas.

\section{INTRODUCTION}

Social determinants of health cause substantial inequalities between and within countries. ${ }^{1}$ In order to quantify and understand these inequalities one must first quantify these social determinants. Measures that are used to do this include education level, income, employment type and various indices of deprivation. In the UK, indices of multiple deprivation and multiple deprivation measures (hereafter, IMD) have been developed encompassing material deprivation and other aspects such as health, education and crime. ${ }^{2}$

The use of these indices is now commonplace in health research in the UK. However, due to the fact that the four constituent nations of the UK have constructed somewhat different indices, direct comparisons between the countries on the basis of these indices is not possible. Further, combining 
data collected from more than one constituent nation within the UK in a single analysis, while making use of a deprivation index, is challenging. Often individuals are placed into groups based on the quintiles of IMD score in the country where they reside and these groups are assumed to be equivalent across nations. However, this would assume that those in the lowest $20 \%$ of deprived areas in one country are subject to the same level of deprivation as those in the lowest $20 \%$ in another country. In other words, it assumes that there are not deprivation gradients between countries in the UK.

To address this situation, we have previously suggested a method by which a single index could be constructed for the UK as a whole. ${ }^{3}$ This method was based on IMD scores based on data between 2008 and 2010. Although a number of studies have made use of these adjusted IMD scores, the scores themselves have not been published and have only been made available by personal communication. Given recent updates to the English, Scottish and Welsh IMDs and the apparent demand for comparable UK scores, we have produced a set of updated UK-wide IMD scores which are publically available from the University of Bristol data repository. ${ }^{4}$ Here we review the methodology used and the application to the updated indices. We also consider how deprivation levels vary in the different nations which make up the UK. Finally, we illustrate the need for our suggested index by comparing premature mortality in different deprivation groups between UK countries.

\section{METHODS}

The IMD are defined for lower layer super output areas (LSOAs) in England and Wales, super output areas (SOAs) in Northern Ireland and data zones in Scotland. These small-area statistical geographies, defined by the national statistics agencies, contain relatively homogenous and small populations. LSOAs have populations of around 1500 people, while SOAs are slightly larger with typical populations of around 2000 people. Scottish data zones are smaller with populations of 500 to 1000 people; unlike LSOAs and SOAs, there are some data zones with no residents.

There are 32844 LSOAs in England and 1909 LSOAs in Wales, with 890 SOAs in Northern Ireland and 6505 data zones in Scotland. We obtained IMD scores and the raw employment and income scores (expressed as percentages) for each country; these data are freely available online.$^{5-8}$ The date of the most current data varies between countries, as does the date of the various underlying indicators which form each of the indices (see online supplementary table S1).

The particular domains and data sources used to create the IMD vary between the UK countries. ${ }^{9}$ However, all four countries give high weight to the income and employment domains (see online supplementary table S2), and the scores for these domains are generally based on similar underlying indicators (table 1). Unlike other domains, scores on these domains are approximately comparable across countries.

A linear regression model was fitted for each country, with IMD score as the dependent variable and income and employment domain scores as independent variables. The residuals from these linear regressions represent the unique contribution of the domains of the IMD score, other than income and employment, to the overall IMD for each country. This is different to the weighted sum of these domains used in the original IMD calculations as these will be correlated with the income and employment domains. Our approach treated all standardised residuals as equivalent between the constituent nations, allowing us to create consistent UK-wide estimates of relative deprivation. Briefly, the regression coefficients from the reference country were applied to the income and employment domain scores for small-area statistical geographies from any country. Added to this was the standardised residual taken from

\begin{tabular}{lllll}
\multicolumn{5}{l}{ Table 1 Components of Indices of Multiple Deprivation income and employment domains } \\
\hline & England 2015 & Northern Ireland 2010 & Scotland 2012 & Wales 2014 \\
\hline Income (weighting) & $(22.5 \%)$ & $(25 \%)$ & $(28 \%)$ & $(23.5 \%)$ \\
Income support & $\checkmark$ & $\checkmark$ & $\checkmark$ & $\checkmark$ \\
Pension credit & $\checkmark$ & $\checkmark$ & $\checkmark$ & $\checkmark$ \\
Jobseeker's allowance & $\checkmark$ & $\checkmark$ & $\checkmark$ & $\checkmark$ \\
Tax credits & $\checkmark$ & $\checkmark$ & & $\checkmark$ \\
Housing benefit & & $\checkmark$ & & $\checkmark$ \\
Asylum seekers support & $\checkmark$ & & $(28 \%)$ & $(23.5 \%)$ \\
Income-based ESA & $\checkmark$ & $(25 \%)$ & $\checkmark$ & $\checkmark$ \\
Employment (weighting) & $(22.5 \%)$ & $\checkmark$ & $\checkmark$ & $\checkmark$ \\
Unemployment-related benefits & $\checkmark$ & $\checkmark$ & $\checkmark$ & \\
ESA & $\checkmark$ & $\checkmark$ & & \\
Incapacity benefit & $\checkmark$ & $\checkmark$ & & \\
Severe disablement Allowance & $\checkmark$ & $\checkmark$ & & \\
Carer's allowance & $\checkmark$ & $\checkmark$ & & \\
New deal participants & & & & \\
ESA, Employment and Support Allowance. & & $\checkmark$ & &
\end{tabular}


the original country regression model, scaled up according to the SD of the residuals in the reference country. Full details of the method are given in box 1 .

The results presented in this article used an adjusted IMD based on the English deprivation index, however, we have also calculated adjusted deprivation indices based on the other nations which we have made available. ${ }^{4}$ After calculating an adjusted IMD score for each small-area statistical geography in Scotland, Wales and Northern Ireland based on the English IMD, we described comparative deprivation levels across the UK using Bland-Altman type plots (where the difference between crude and adjusted scores is plotted against the mean of those two scores) and by tabulating what proportion of each country live in groups defined by UK-wide quintiles of deprivation.

We illustrated the potential shortcomings of the naive approach to comparisons between countries using country-specific deprivation quintiles for each country. As average deprivation levels may differ between countries, this may give misleading results. To do this we compared age standardised under-75 mortality rates by deprivation quintile between England, Northern Ireland, Scotland and Wales based on country-specific IMD quintiles and UK-adjusted quintiles. Rates were standardised to the UK age structure from 2011 to 2013, based on small area population estimates and death registrations obtained from the relevant national statistics agencies (Northern Ireland Statistics and Research Agency, death registrations by SOA and single year of age 2011 to 2013, personal communication, 2016; National Records of Scotland, death registrations by data zone and single year of age 2011 to 2013, personal communication, 2016). ${ }^{10-14}$

Box 1 Details of calculation of adjusted Indices of Multiple Deprivation (IMD) scores

Our approach is based on the following linear regression model

$$
I \mathrm{MD}_{\mathrm{Ci}}=\beta_{\mathrm{C} 0}+\beta_{\mathrm{C} 1} \mathrm{I}_{\mathrm{i}}+\beta_{\mathrm{C} 2} \mathrm{E}_{\mathrm{i}}+\epsilon_{\mathrm{Ci}}
$$

where: $I M D_{C i}$ is the IMD score for area $i$ in country $C ; I_{i}$ is the area's score on the income domain; $E_{i}$ is the area's score on the employment domain; $\beta_{\mathrm{C} 0}, \beta_{\mathrm{C} 1}$ and $\beta_{\mathrm{C} 2}$ are model coefficients; and $\epsilon_{\mathrm{Ci}} \sim \mathrm{N}\left(0, \sigma_{\mathrm{C}}^{2}\right)$ is the residual value.

We assume that any area i would have the same standardised position in the residual distribution in any country, if the same regression approach was used for both countries. For example, if the area $i$ is in Wales (W), then the assumed residual for the same area on the English (E) IMD scale would be given by

$$
\epsilon_{E i}=\sigma_{E} \times \frac{\epsilon_{W i}}{\sigma_{W}}
$$

Based on this assumption, we may estimate the IMD score for the Welsh area i on the English IMD scale as

$$
I M D_{E i}=\beta_{E 0}+\beta_{E 1} l_{i}+\beta_{E 2} E_{i}+\sigma_{E} \times \frac{\epsilon_{W i}}{\sigma_{W}}
$$

All analysis was performed in Stata V.13 (Stata Statistical Software: Release 13. College Station, Texas: StataCorp LP, 2013).

\section{RESULTS}

\section{Association between income and employment domain scores and IMD}

There was substantial variation in the regression coefficients between each country. However, linear combinations of the raw income and employment scores accounted for at least $94 \%$ of the within-country variance (table 2).

Investigation of residuals plots suggested small problems with the model fit. In particular, the IMD score is constrained to lie between 0 and 100 leading to lower residual variance for areas with low IMD scores. Additionally, there was some suggestion of non-linear associations between income and employment scores and IMD scores. Interactions between income and employment, as well as quadratic income and employment terms, were considered; these produced models with marginally improved fit (see online supplementary appendix 1). However, we felt that using a simple model was preferable given that the improvement in $\mathrm{R}^{2}$ values was on the order of 0.005 (ie, the practical significance of including these additional terms was small).

\section{UK-wide comparison of deprivation}

Comparison of UK-adjusted IMD scores based on the England index showed that for Scotland, the UK-adjusted scores were generally similar to the countryspecific scores (figure 1). For Wales, UK-adjusted scores tended to be slightly higher. For Northern Ireland, UK-adjusted scores were typically considerably higher than country-specific scores, particularly for the more deprived areas within Northern Ireland. Table 3 shows the proportion of each country's population in each UK-wide quintile. Overall, England and Scotland had relatively similar levels of deprivation using our adjusted IMD score. Both countries were slightly less deprived than the UK as a whole. Wales was considerably more deprived than either Scotland or England. Just $7 \%$ of the Welsh population were in one of the least deprived fifth of areas across the UK, although the proportion of people in the most deprived quintile was only marginally higher than for England or Scotland. Northern Ireland was the most deprived of all the UK countries. None of the areas in Northern Ireland were in the least deprived fifth of the UK, while $36.6 \%$ of the population of Northern Ireland were in the most deprived fifth of the UK.

\section{Comparison of mortality rates between constituent countries of the UK by deprivation quintile}

Comparison of age-standardised mortality rates among people aged under 75 years showed that using countryspecific deprivation groups may give very misleading 
Table 2 Relationship between Indices of Multiple Deprivation and income/employment scores in each UK country

\begin{tabular}{|c|c|c|c|c|c|}
\hline & \multicolumn{3}{|c|}{ Regression coefficients } & \multirow[b]{2}{*}{$\begin{array}{l}\text { Residual SD } \\
\left(\sigma_{\mathrm{C}}\right)\end{array}$} & \multirow[b]{2}{*}{$\begin{array}{l}\text { Proportion of variance } \\
\text { explained }\left(R^{2}\right)\end{array}$} \\
\hline & $\begin{array}{l}\text { Intercept } \\
\left(\beta_{\mathrm{C}{ }^{*}}\right)\end{array}$ & $\begin{array}{l}\text { Income } \\
\left(\beta_{\mathrm{C} 1}{ }^{*}\right)\end{array}$ & $\begin{array}{l}\text { Employment } \\
\left(\beta_{\mathrm{C} 2}{ }^{*}\right)\end{array}$ & & \\
\hline England & -0.57 & 1.01 & 0.63 & 3.73 & 0.94 \\
\hline Northern Ireland & -6.60 & 0.72 & 0.76 & 2.85 & 0.97 \\
\hline Scotland & -1.62 & 0.89 & 0.83 & 3.09 & 0.96 \\
\hline Wales & -4.79 & 1.06 & 0.60 & 3.68 & 0.94 \\
\hline
\end{tabular}

results (table 4). Country-specific deprivation groups in Northern Ireland and Wales had higher mortality rates than similar groups in England, but when comparing equivalent UK-adjusted deprivation groups mortality rates were substantially lower in Northern Ireland than England and the difference in mortality rates between England and Wales was much reduced. Country-specific and UK-adjusted deprivation groups gave similar results when comparing mortality rates in Scotland and England.

\section{DISCUSSION}

\section{Summary of key results}

We calculated adjusted IMD scores appropriate for comparisons across the UK from publically available data sets, and compared deprivation levels, and deprivation-group-specific mortality rates, between the UK countries.

Our results demonstrate that using country-specific IMD for between-country comparisons may give misleading results with respect to health outcomes. For example, Welsh mortality rates appear higher than English ones when using country-specific IMD primarily because Wales is in general more deprived than England. In comparison, when using UK-adjusted IMD groups the difference in mortality rates is considerably smaller.
In the context of published work

Our results here are an update to previously published work describing this approach to calculating UK-adjusted IMD scores. ${ }^{3}$ In this analysis, we use more recent versions of IMD and empirically show the impact of using UK-adjusted IMD scores for between-country comparisons. If we compare the regression coefficients from this study (table 2) to those in the previous work (table 1 of previous paper ${ }^{3}$ ), we find that some regression coefficients change substantially. However, there is very little change in the proportion of variance explained between the original and this study. This almost certainly reflects the fact that there is a degree of collinearity between the two domains and the exact weighting with which they are combined matters little. Our finding that Wales and NI are more deprived than England and Scotland was also shown in our previous study. ${ }^{3}$

It is important to judge whether our artificial measure accurately reflects deprivation levels in UK countries. Our country-level results suggest that England and Scotland have similar levels of deprivation, Wales is more deprived and Northern Ireland is the most deprived of the UK countries with no areas in the least deprived $20 \%$ of the UK. This is consistent with the productivity, employment rate and gross disposable household income per head of the four countries as
Figure 1 Bland-Altman-style plots of country-specific Indices of Multiple Deprivation (IMD) and UK-adjusted IMD scores, based on England.

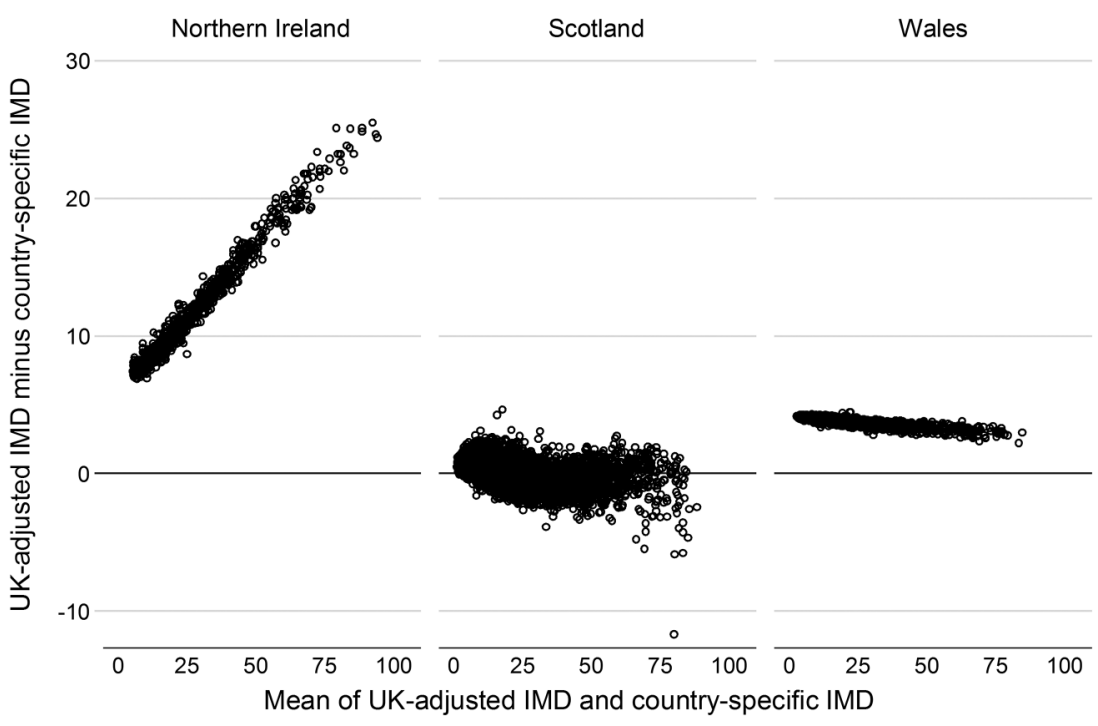


Table 3 Percentage of population (average over 2011-2013) living in areas in each deprivation quintile by country, according to a UK-adjusted Indices of Multiple Deprivation (IMD) score based on England

\begin{tabular}{llllll}
\hline UK-adjusted IMD quintile & England & Northern Ireland & Scotland & Wales & UK \\
\hline 1-least deprived & 21.4 & 0.0 & 20.8 & 7.0 & 20.0 \\
2 & 20.1 & 15.0 & 21.6 & 18.8 & 20.0 \\
3 & 19.4 & 19.1 & 21.8 & 27.3 & 20.0 \\
4 & 19.6 & 29.2 & 17.8 & 25.0 & 20.0 \\
5-most deprived & 19.5 & 36.6 & 18.2 & 21.9 & 20.0 \\
Total population & $\mathbf{5 3 4 8 8 \mathbf { 8 3 9 }}$ & $\mathbf{1 8 2 2} \mathbf{5 6 1}$ & $\mathbf{5 3 1 3 \mathbf { 7 4 2 }}$ & $\mathbf{3 0 7 3 \mathbf { 4 0 5 }}$ & $\mathbf{6 3 6 9 8 5 4 7}$ \\
\hline
\end{tabular}

well as figures such as the proportion of the population with no qualifications. ${ }^{15}$

We found that, when comparing similar deprivation groups, Scotland had considerably higher mortality than England for each group. This agrees with other studies using different data sources. For example, an analysis of the Health Survey for England and the Scottish Health Survey found higher mortality rates in Scotland after controlling for the person-level National Statistics Socio-economic Classification. ${ }^{16}$

\section{Strengths and limitations}

A strength of our approach to estimating the relative deprivation levels of areas within the UK is the transparent method and the use of publically available data sets. This gives a simple way of obtaining comparable measures of area-based deprivation across the UK, which is straightforward to update as new data become available.

The main weakness of our approach is that the underlying data sets do not necessarily relate to the same time periods, with the country-specific measures used here being published between 2010 and 2015. Further, the underlying data for individual domains of the deprivation indices come from varying periods prior to publication (see online supplementary table S1). Note, however, that area-based deprivation is relatively consistent between versions of IMD, with $83 \%$ of areas in the most deprived decile of England according to the 2010 IMD also in the most deprived decile of England according to the 2015 IMD and all of these areas still being in the most deprived $30 \%$ of areas. ${ }^{6}$ That said given the economic changes occurring in the past decade there may be particular challenges posed by the fact that the income and employment data underlying the countryspecific IMDs relate to different periods (2008/2009 for Northern Ireland, 2010/2011 for Scotland and 2012/ 2013 for England and Wales). Changes in the economy over that period means that these data may not be directly comparable. For example, the unemployment benefits claimant rate in Northern Ireland was $4.1 \%$ in December 2008, compared with $3.6 \%$ for the UK, while in December 2012 it was $7.4 \%$, compared with $4.7 \%$ for the UK. ${ }^{17}$ When adjusted deprivation indices are used this limitation should always be borne in mind.

\section{Interpretation and implications}

The UK-adjusted deprivation scores we describe provide a valid, consistent approach to describing deprivation across the UK. These scores allow appropriate adjustment for deprivation when comparing between UK

Table 4 Age-standardised mortality rates (ASMRs) per 100000 in constituent countries of the UK, 2011-2013, by country-specific IMD quintiles and by UK-adjusted IMD quintiles based on England

\begin{tabular}{|c|c|c|c|c|c|c|c|}
\hline & \multicolumn{4}{|c|}{ Under-75 ASMRs* } & \multicolumn{3}{|c|}{ Difference relative to England } \\
\hline & England & Northern Ireland† & Scotland & Wales & Northern Ireland & Scotland & Wales \\
\hline \multicolumn{8}{|c|}{ Country-specific IMD quintiles } \\
\hline 1-least deprived & 205.3 & 238.1 & 238.0 & 234.5 & 32.8 & 32.6 & 29.2 \\
\hline 2 & 244.6 & 290.5 & 295.5 & 274.4 & 45.8 & 50.9 & 29.8 \\
\hline 3 & 286.0 & 320.0 & 370.7 & 327.6 & 34.0 & 84.7 & 41.6 \\
\hline 4 & 358.3 & 366.0 & 486.2 & 406.8 & 7.6 & 127.9 & 48.5 \\
\hline 5-most deprived & 489.0 & 527.9 & 649.6 & 509.8 & 39.0 & 160.6 & 20.9 \\
\hline \multicolumn{8}{|c|}{ UK-adjusted IMD quintiles based on England } \\
\hline 1-least deprived & 207.2 & $\ddagger$ & 240.0 & 200.5 & $\ddagger$ & 32.8 & -6.7 \\
\hline 2 & 247.9 & 236.1 & 302.6 & 256.7 & -11.8 & 54.7 & 8.8 \\
\hline 3 & 290.6 & 273.2 & 376.8 & 297.8 & -17.4 & 86.2 & 7.2 \\
\hline 4 & 362.9 & 322.0 & 501.9 & 382.0 & -40.9 & 139.1 & 19.1 \\
\hline 5-most deprived & 491.4 & 448.6 & 655.9 & 502.9 & -42.8 & 164.5 & 11.5 \\
\hline
\end{tabular}

*Standardised to UK age structure over 2011 to 2013.

†Based on 2011 census populations rather than mid-year estimates.

$\ddagger$ No areas in Northern Ireland were in the least deprived fifth of the UK.

IMD, Indices of Multiple Deprivation. 
countries. This approach is of value in determining the impact of socioeconomic deprivation on health outcomes across the UK, which cannot be readily achieved through the use of country-specific deprivation scores.

Contributors GAA and RAP conceived the work. MEB acquired data and performed the analysis. All authors contributed to drafting the work and gave final approval.

Funding This research received no specific grant from any funding agency in the public, commercial or not-for-profit sectors.

Competing interests None declared.

Provenance and peer review Not commissioned; externally peer reviewed.

Data sharing statement Datasets used in this work are freely available from the relevant national statistics agencies. UK-adjusted deprivation scores and quintiles, based on each UK country, are available from the University of Bristol data.bris Research Data Repository, https://data.bris.ac.uk/data/, DOI: 10.5523/bris.1ef3q32gybk001v77c1ifmty7x.

Open Access This is an Open Access article distributed in accordance with the Creative Commons Attribution Non Commercial (CC BY-NC 4.0) license, which permits others to distribute, remix, adapt, build upon this work noncommercially, and license their derivative works on different terms, provided the original work is properly cited and the use is non-commercial. See: http:// creativecommons.org/licenses/by-nc/4.0/

\section{REFERENCES}

1. Marmot M. Social determinants of health inequalities. Lancet 2005;365:1099-104.

2. Noble M, Wright G, Smith G, et al. Measuring multiple deprivation at the small-area level. Environ Plann A 2006;38:169-85.

3. Payne R, Abel G. UK indices of multiple deprivation-a way to make comparisons across constituent countries easier. Health Stat $Q$ 2012:22. http://ons.gov.uk/ons/rel/hsq/health-statistics-quarterly/ no--53--spring-2012/uk-indices-of-multiple-deprivation.html (accessed 15 Mar 2016).

4. data.bris Research Data Repository. https://data.bris.ac.uk/data/. doi: 10.5523/bris.1ef3q32gybk001v77c1 ifmty7x

5. Office of the Chief Statistician and Performance. Scottish index of multiple deprivation 2012. 2012. http://simd.scotland.gov.uk/ publication-2012/ (accessed 7 Mar 2016).
6. Department for Communities and Local Government. English indices of deprivation 2015. 2015. https://www.gov.uk/government/statistics/ english-indices-of-deprivation-2015

7. Northern Ireland Statistics and Research Agency. Northern Ireland multiple deprivation measure 2010. 2010. http://www.nisra.gov.uk/ deprivation/nimdm_2010.htm (accessed 7 Mar 2016).

8. Welsh Government. Welsh index of multiple deprivation 2014. 2015. http://gov.wales/statistics-and-research/welsh-index-multipledeprivation/?lang=en (accessed 7 Mar 2016).

9. Office for National Statistics. Similarities and differences between the Indices of Deprivation across the UK. 2015. http://www. neighbourhood.statistics.gov.uk/dissemination/Info.do? page=analysisandguidance/analysisarticles/indices-of-deprivation . htm (accessed 7 Mar 2016).

10. Northern Ireland Statistics and Research Agency. Usually resident population by single year of age and sex (statistical geographies) 2011. http://www.ninis2.nisra.gov.uk/Download/Census\%202011/ Usually\%20Resident\%20Population\%20by\%20single\%20year\%20o \%20age\%20and\%20sex\%20(statistical\%20geographies).ods (accessed 7 Mar 2016).

11. Office for National Statistics. Deaths by LSOA, sex and age, Wales, 1981-2013. 2015. http://webarchive.nationalarchives.gov.uk/ 20160105160709/http://www.ons.gov.uk/ons/about-ons/businesstransparency/freedom-of-information/what-can-i-request/publishedad-hoc-data/health/march-2015/index.html (accessed 7 Mar 2016).

12. Office for National Statistics. Deaths by LSOA, 1981-2013. 2015. http://webarchive.nationalarchives.gov.uk/20160105160709/http:// www.ons.gov.uk/ons/about-ons/business-transparency/ freedom-of-information/what-can-i-request/published-ad-hoc-data/ health/january-2015/index.html (accessed 7 Mar 2016).

13. National Records of Scotland. Mid-2011 to mid-2014 small area population estimates Scotland. 2015. http://www.nrscotland.gov.uk/ statistics-and-data/statistics/statistics-by-theme/population/ population-estimates/2011-based-special-area-population-estimates/ small-area-population-estimates/mid-2011-to-mid-2014/ detailed-data-zone-tables (accessed 7 Mar 2016).

14. Office for National Statistics. Lower super output area mid-year population estimates. 2015. http://www.ons.gov.uk/ peoplepopulationandcommunity/populationandmigration/ populationestimates/datasets/lowersuperoutputareamidy earpopulationestimates (accessed 7 Mar 2016).

15. Office for National Statistics. Compendium of UK statistics. 2014 http://ons.gov.uk/ons/guide-method/compendiums/ compendium-of-uk-statistics/index.html (accessed 7 Mar 2016)

16. McCartney G, Russ TC, Walsh D, et al. Explaining the excess mortality in Scotland compared with England: pooling of 18 cohort studies. J Epidemiol Community Health 2015;69:20-7.

17. Office for National Statistics. NOMIS Labour Market ProfileNorthern Ireland. 2016. https://www.nomisweb.co.uk/reports/lmp/gor/ 2013265932/report.aspx (accessed 12 Aug 2016). 